\title{
DETERMINATION OF EMITTER HYDRAULIC PROPERTIES OF DIFFERENT IN-LINE DRIPPER TYPES
}

\author{
AYDIN, Y. \\ Siirt University, Faculty of Agriculture, Department of Biosystem Engineering \\ Siirt 56100, Turkey \\ e-mail: yusufaydin@siirt.edu.tr; phone: +90-484-212-1111; fax: +90+484-223-1998
}

(Received 16 ${ }^{\text {th }}$ Apr 2019; accepted $13^{\text {th }}$ Jun 2019)

\begin{abstract}
It is only possible by way of highly efficient system performance to provide uniform water distribution and sufficient soil moisture at the plant root zone in drip irrigation systems. Factors related with hydraulic and the emitter performance change should be known well for determining irrigation uniformity. In the study, 4 different emitter laterals were tested under 4 different pressure loads (5-10-15 and $20 \mathrm{~m}$ ). The accordance of flow characteristics for the laterals, manufacturing variety coefficient $(\mathrm{CV})$, emitter uniformity (EU) and irrigation water uniform distribution coefficient or Cristiansen Uniformity Coefficient (CU) and Statistical Uniformity (Us) values were evaluated in with regard to the American Society of Agricultural Engineers standards. It was determined based on the acquired results that there is an increase in the flow rates of emitters corresponding to the increasing pressure values and it was also determined that there were differences ranging between $0.75 \%$ to $25.5 \%$ with the flow values provided by manufacturing companies under $1 \mathrm{~atm}$ pressure. While the manufacturing variety coefficient class values were "weak", "moderate" and "good" for the A emitter, class values of "good" and "very good" were determined for irrigation uniformity (CU) and emitter uniformity (EU).
\end{abstract}

Keywords: operating pressure, uniformity, drip irrigation, flow-rate, test-table

\section{Introduction}

Recently, irrigation is also considered as, "maintaining the usable water at a suitable level at the root zone in addition to providing the water required for plant production". Irrigation applications are carried out using different methods due to changes in the topographic structure of the land, soil and plant type as well as changes in farmer preferences and cost factors. Among these methods, drip irrigation is preferred due to its superiorities over other methods with regard to yield, efficiency, irrigation water savings when compared with other irrigation methods, it is indicated that drip irrigation provides $44 \%$ water savings on apple trees in comparison with other surface irrigation methods (Mohammed, 2018), whereas drip irrigation consumes 60\% less water in grapevine irrigation compared with furrow irrigation and $56 \%$ less water compared with micro sprink irrigation (Baştuğ et al., 1998). In general, about 30-60\% water saving is possible with drip irrigation method in comparison to sprinkling and flood irrigation in agricultural irrigation (Anonymous, 2004). Drip irrigation is defined as, "slowly delivering filtered water to the plant roots in small amounts and at high intervals". Deep percolation, surface flow and evaporation losses can be minimized with this method (Wu et al., 1979; Korukçu, 1980; cited from Altın, 2009). Uniform distribution of water is a desired characteristic in drip irrigation. Failure of the system to distribute the water uniformly results in excessive or deficit irrigation of the plant roots. Both cases will inevitably yield to the emergence of conditions that are not suited for plant growth. Excessive irrigation leads to insufficient aeration of the roots due to bad drainage, washing of nutrients at the root and thereby reduced effectiveness of the fertilizer, while deficit irrigation results in higher energy consumption and low irrigation efficiency 
(Çiçek, 2015). Hence, hydraulic change and emitter performance change should be taken into consideration as two important parameters causing changes in emitter flow rates when determining irrigation uniformity which is an important element when evaluating the drip irrigation system performances. Hydraulic change develops due to the pressure change resulting from the incline of side pipes and laterals on the land as well as pipe diameter and lateral length. Whereas emitter performance change can be considered as changes in emitters due to factors such as manufacturing varieties of emitters, level of clogging due to irrigation water, changes in irrigation water temperature and wear in emitters over time (Çamoğlu and Yavuz, 2004). Similarly, many factors such as operating pressure, water chemical and temperature, construction changes, effecting the uniformity of water distrubition. Therefore, the lack of such mentioned factors that caused to poor desing will bring changing in discharge and the distribution uniformity and low irrigation efficiency. The uniformity parameters are the main and basic criteria for designing an efficient of drip irrigation system (Elamin et al., 2017). Ideally, all emitters in a drip irrigation system should have equal flow rates (Özekici and Bozkurt, 1996). However, this is not possible in practice. Accurate emitter manufacturing is the main criteria and necessary in order to ensure a high effective system uniformity. Also the emission uniformity is essential to determining the total dept of water applied (Yeeshu et al., 2014). Manufacturing varieties that have a significant impact on system performance also cause variations in emitter flow rates. Emitters may differ with regard to characteristics such as volume, weight, surface shape and length due to factors such as raw materials used in manufacturing, manufacturing temperature, mold properties, manufacturing pressure and rate, cooling time etc. (Demir and Yürdem, 2000). There may be flow regime differences even in two emitters manufactured with the same technology using the same machine and the same manufacturing conditions (Solomon, 1979; Özekici and Sneed, 1995). Uniform distribution of irrigation water is one of the primary criteria taking into consideration when evaluating irrigation systems. However, irrigation systems differ with regard to uniform distribution due to many different reasons. Factors such as the uniform distribution of water at the application area, friction losses at the side pipe and laterals of the system, pressure changes due to the elevation differences between system elements, how well the system is maintained, level of clogs in the emitter due to contamination of irrigation water and the number of emitters per plant affect the uniform distribution of water (Ünal, 2011). It is also inevitable that there will be differences between local and foreign emitter laterals due to factors such as manufacturing conditions, raw material and manufacturing temperature even if they have been manufactured using similar technologies.

The purpose of this study was to put forth the impacts of manufacturing differences among emitters on their irrigation performances and to provide information to users on the different types of emitters in the market by carrying out analyses on their operating performances under different operating pressures as well as various hydraulic performance parameters. In the literature review, resently, there is no study in the GAP region which is compatible with the subject of this study or to determine the dripper hydraulic performances. There are large agricultural areas where pressurized irrigation systems are used in the region. Considering the excess amount of dripper lateral to be used in these areas, the use of drippers with good hydraulic performance is very important in terms of protection of water resources and providing the expected benefit from irrigation. 


\section{Materials and Methods}

\section{Test setup preparation}

The present study was carried out at Siirt University which is located in the Southest Anatolia Region of Turkey Faculty of Agriculture Department of Biosystem Engineering irrigation laboratory. The test table in the laboratory (Fig. 1) was arranged such that the specially manufactured 4 lateral lines with an elevation of $1.2 \mathrm{~m}$ from ground level, lenght of $6 \mathrm{~m}$ and width of $1.8 \mathrm{~m}$ can be tested simultaneously.

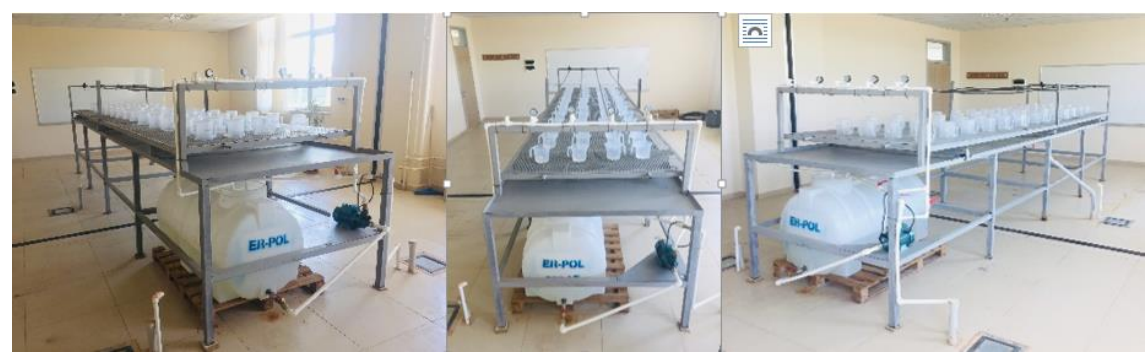

Figure 1. A view of test table used in this study

The test setup was comprised of a main pipe, mounting system and lateral pipe lines. A $32 \mathrm{~mm}$ PPRC (Polypropylene Random Copolymer) pipe integrated to the municipal water outlet at the laboratory which is controlled by a ball valve was used as the main pipeline. The mounting system was affixed from its starting and ending points using a steel wire to make the incline at the laterals zero and the test laterals were fixed on these steel wires via clips. The test table for steel wires and laterals was mounted on a moving table at an elevation of $40 \mathrm{~cm}$ and a setup with 4 rows was prepared with lateral gaps of $35 \mathrm{~cm}$. Plastic ball valves and manometers were used as return valve on the end of the main pipeline for pressure control at the lateral inlets and for ensuring lateral safety under high pressure conditions. The municipal water used in the test setup was directly connected since there was no contamination that may cause clogging. An additional electrical pump was not used in the system since the municipal operating pressure may reach up to 6 bars, however a $2 \mathrm{~kW}$ electrical pump was integrated to the system as a precaution against pressure drops. The municipal pressure was applied on the laterals after being reduced to the desired test pressure via ball valves. Temperature changes in the municipal water were monitored during the test at varying intervals using a portable thermometer and a difference of $\pm 0.5^{\circ} \mathrm{C}$ was not included in the calculations since it is not effective on flow rate changes. Transparent plastic cups of 1.2 liters were used for collecting the water from the emitters.

\section{Execution of the tests}

Lateral flow rate tests were carried out at 4 different pressure intervals (5-10-15 and $20 \mathrm{~m}$ ) on emitters the characteristics of which are given in Table 1.

A total of 28 emitters were selected on each lateral for determining the relationship between emitter pressure - flow rate and measurements were carried out with 3 repetitions. Water was given to the system which was subject to 10 minutes of natural dripping prior to starting the measurements and it was waited until the lateral input pressures became constant. Measurements were started and stopped simultaneously for all laterals. The emitter flow rates were determined in accordance with the volume 
principle using the amount of water accumulated in drip pans placed under the laterals by way of $10 \mathrm{ml}$ graded $1000 \mathrm{ml}$ glass beakers (Tekin et al., 2016). The flow rate values determined for each emitter were evaluated in Excel software after which the flow regime, flow index subject to flow regime $(\mathrm{x})$, flow coefficient $(\mathrm{k})$, correlation coefficient (r), emitter uniformity (EU), Cristiansen Uniformity coefficient (CU), statistical uniformity coefficient (Us), manufacturing variety coefficient $(\mathrm{CV})$ values were determined and the changes in these values subject to pressure were evaluated.

Table 1. Characteristics of the emitters used in the test

\begin{tabular}{c|c|c|c|c}
\hline Emitter name & Flow rate( $\left.\mathbf{~ h}^{\mathbf{- 1}}\right)$ & Emitter distance (m) & Type of lateral & Emitter Type \\
\hline A (local) & 4 & 0.33 & Round & in-line-no diaphragm \\
B (local) & 4 & 0.33 & Round & in-line-no diaphragm \\
C (foreign) & 4 & 0.33 & Round & in-line-no diaphragm \\
D (foreign) & 4 & 0.33 & Round & in-line-no diaphragm \\
\hline
\end{tabular}

\section{Determination of emitter flow characteristics}

Emitter flow rate is a function of the pressure that characterizes flow. Hence, certain emitter characteristics such as manufacturing variety, emitter parameters can be easily determined via experimental studies (Karaca, 2008). The relationship between emitter inlet pressure and emitter flow rate is defined as a flow characteristic and is indicated with the $\mathrm{Q}=\mathrm{kh}^{\mathrm{x}}$ equality given in Table 2 and calculated using Eq.1. Here; Q: emitter flow rate, $(\mathrm{l} / \mathrm{h})$; $\mathrm{k}$ : coefficient expressing emitter dimensions, h: emitter inlet pressure $(\mathrm{m})$ and $\mathrm{x}$ : emitter flow regime coefficient. The values of $\mathrm{k}$ and $\mathrm{x}$ indicate emitter characteristics and are two important parameters with an impact on uniform water distribution in drip irrigation as coefficients indicating emitter flow regime (Demir and Yürdem, 2000).

Table 2. Hydraulic parameters and equations used in calculation

\begin{tabular}{|c|c|c|}
\hline Hydrolic parameters & Equations & \\
\hline Flow Equation (Korukçu, 1980; Bralts, 1986) & $Q=k h^{x}$ & (Eq.1) \\
\hline Manufacturing Variety Coefficient (CV) (ASAE, 2002) & $C v=\frac{S}{X_{\text {ort }}}$ & (Eq.2) \\
\hline Emitter uniformity (EU) (Keller and Karmeli, 1974) & $E U=100 * \frac{q_{x}}{q_{a}}$ & (Eq.3) \\
\hline Irrigation water distrubition uniformity (CU) (Cristiansen, 1942) & $C U=100\left(1-\frac{\Delta q_{0}}{q_{a}}\right)$ & (Eq.4) \\
\hline Statistical Uniformity (Us) (Bralts and Kesner, 1983) & $U s=100\left(1-\frac{s_{q}}{q_{\text {ont }}}\right)$ & (Eq.5) \\
\hline
\end{tabular}

In the above equations; $\mathrm{q}$ : emitter flowrate $\left(\mathrm{l} \mathrm{h}^{-1}\right)$; $\mathrm{k}$ : flow coefficient; $\mathrm{h}$ : operating pressure, $\mathrm{m}$; $\mathrm{x}$ : flow index subject to flow regime; $\mathrm{q}_{\mathrm{x}}$ : average of $1 / 4$ of the emitters with the lowest flow rate $\left(1 \mathrm{~h}^{-1}\right)$; $\mathrm{q}_{\mathrm{a}}$ : average of all emitter flow rates, $\left(1 \mathrm{~h}^{-1}\right) ; \Delta \mathrm{q}_{\mathrm{o}}$ : average of the absolute deviations from the average for each emitter or lateral flow rate, $\mathrm{q}_{\mathrm{o}}$ : emitter or lateral input flow rate average, $\left(1 \mathrm{~h}^{-1}\right)$; $\mathrm{S}_{\mathrm{q}}$ : standard deviation of emitter flow rates; qort average emitter flow rate $\left(1 \mathrm{~h}^{-1}\right) ; \mathrm{X}_{\text {ort }}$ : average emitter flow rate; $\left(1 \mathrm{~h}^{-1}\right)$; S: standard deviation of emitter flow rates

Flow index values suggested by different researchers that define emitter flow rate characteristics are given in Table 3. Results for the flow regime obtained in the study were evaluated according to Table 3 and the flow regimes of the laterals used were determined. 
Table 3. Emitter flow regime coefficient values (Demir and Yürdem, 2000; Karaca, 2008)

\begin{tabular}{c|c} 
Flow Regime & x value \\
(Bralts et al., 1987)
\end{tabular}

The evaluation principles provided in Table 4 were used when determining emitter hydraulic parameters and the numerical values acquired as a result of the calculations were classified according to the provided criteria.

Table 4. Recommended limits of coefficients (Tüzel, 1993; ASAE, 1994, 2002)

\begin{tabular}{c|c|c|c|c}
\hline Classification & CV (\%) & Us (\%) & EU (\%) & CU (\%) \\
\hline Very good & $<5$ & $100-95$ & $\geq 94$ & $>90$ \\
Good & $5-7$ & $90-85$ & $81-77$ & $80-90$ \\
Moderate & $7-11$ & $80-75$ & $68-75$ & $70-80$ \\
Weak & $11-15$ & $70-65$ & $56-62$ & $60-70$ \\
Unacceptable & $>15$ & $<60$ & $\leq 50$ & $<60$ \\
\hline
\end{tabular}

\section{Results and Discussion}

\section{Emitter flow characteristics}

Table 5 summarizes the results related with flow characteristics for the emitters used in the study. Flow index values were determined between $0-0.5$ for the $\mathrm{B}, \mathrm{C}$ and $\mathrm{D}$ emitters used in the study and display a partially turbulent flow characteristic without pressure regulator. The flow index $(\mathrm{x})$ value determined via graphic method for the emitter of A company was 0.5035 and it was evaluated to have a full turbulent flow regime.

Table 5. Flow properties of emitters

\begin{tabular}{c|c|c|c|c}
\hline \multirow{2}{*}{} & \multicolumn{4}{|c}{ Flow properties of emitters } \\
\cline { 2 - 5 } & A (local) & B (local) & C (foreign) & D (foreign) \\
\hline Flow regime & Full Turbulence & Partial Turbulence & Full Turbulence & Full Turbulence \\
Flow equations & $\mathrm{q}=1.6811 * \mathrm{~h}^{0.5035}$ & $\mathrm{q}=1.3305 * \mathrm{~h}^{0.4529}$ & $\mathrm{q}=1.3308 * \mathrm{~h}^{0.4684}$ & $\mathrm{q}=1.386 * \mathrm{~h}^{0.4706}$ \\
$\mathrm{k}$ & 1.6811 & 1.3305 & 1.3308 & 1.386 \\
$\mathrm{x}$ & 0.5035 & 0.4529 & 0.4686 & 0.4706 \\
$\mathrm{R}^{2}$ & 0.9795 & 0.9869 & 0.9881 & 0.9667 \\
\hline
\end{tabular}

\section{Pressure-Flow Rate relationship}

The emitters used in the study were tested under 4 different operating pressures and the acquired results have been summarized in Table 6 and Figure 2. It can be observed upon examining the pressure-flow rate change of emitters that different values have been obtained at different operating pressures. Whereas the lowest average flow rate value was $2.791 \mathrm{~h}^{-1}$ for the $\mathrm{B}$ emitter at the lowest operating pressure $(5 \mathrm{~m})$, the highest 
average flow rate value was obtained as $7.73 \mathrm{l} \mathrm{h}^{-1}$ for the A emitter at an operating pressure of $20 \mathrm{~m}$.

As can be seen in Table 6, the flow rate values determined during the study carried out for determining the flow characteristics of the emitters displayed a tendency to increase with increasing operating pressure. Parallel to the developments in irrigation technologies, studies have been carried out by many researchers for determining the variation in emitter pipes as well as the flow characteristics of these emitters (Özekici and Sneed, 1995; Demir and Yürdem, 2000; Kırnak et al., 2004; Üğlü and Tanrıverdi, 2013; Tekin et al., 2016). It was put forth in studies carried out by researchers that flow rate changes especially in systems using emitters without pressure regulator tended to increase with increasing operating pressure. Results acquired in this study regarding the pressure-flow rate changes were in accordance with the findings of other researchers and an increase was observed in emitter flow rates corresponding to an increase in operating pressure.

Table 6. Emitters' pressure-flow relationship

\begin{tabular}{ccccc}
\hline \multirow{2}{*}{$\begin{array}{c}\text { Pressure } \\
(\mathbf{m})\end{array}$} & A (local) & B (local) & C (foreign) & D (foreign) \\
\cline { 2 - 5 } & 3.89 & 2.79 & 2.87 & 3.02 \\
15 & 5.02 & 3.75 & 3.86 & 4.03 \\
10 & 6.70 & 4.36 & 4.57 & 4.65 \\
15 & 7.73 & 5.35 & 5.61 & 6.02 \\
\hline
\end{tabular}
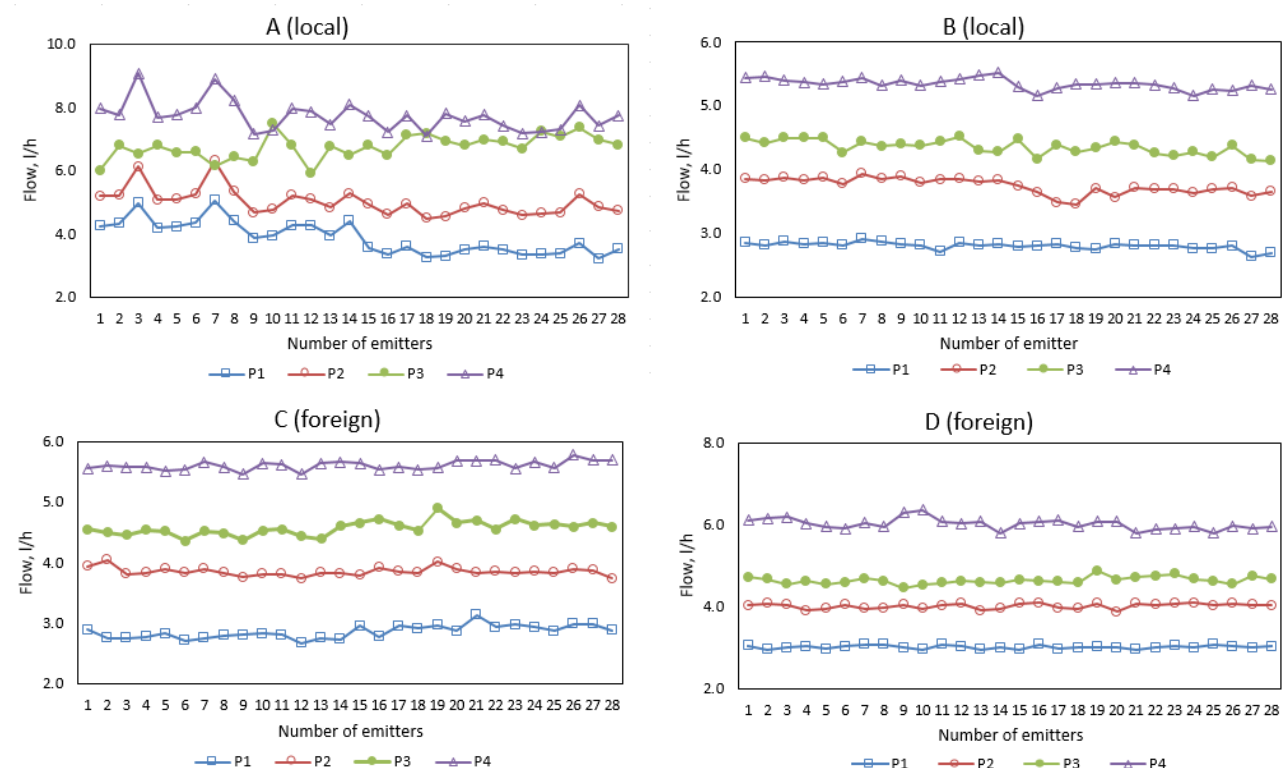

Figure 2. Pressure-flow change in foreign dripper pipes

Even though the flow rate for 1 atm pressure suggested by manufacturers of the emitters used in the study was $41 \mathrm{~h}^{-1}$, deviations from this value were observed. While the highest \% change from the suggested flow rate was observed for the A emitter with $25.5 \%$, the lowest change \% was observed for the $\mathrm{D}$ emitter with $0.75 \%$. The aforementioned values are similar with the findings of Tekin et al. (2016). Researchers 
determined this change to vary between $1-15.5 \%$ subject to the companies of emitters used. The sudden decrease and increase in emitter B shown in Figure 2 is thought to be due to the instantaneous pressure change in the emitter. The preference of emitters by system users with less flow rate change and which are classified as either "good" or "very good" should be taken into consideration with regard to both system performance and first facility cost.

\section{Manufacturing variety coefficient}

The manufacturing variety coefficients of the emitters used in the study were calculated using Eq.2 and evaluated according to Wu and Gittling (1974) and ASAE (1994) and the manufacturing variety coefficients (CV) acquired along with classification have been given in Table 7. As can be seen when the table is examined that the CV coefficients have been subject to an evaluation based on different classification groups and received group values ranging between "very good" and "unacceptable". The emitters were classified into 4 groups as a result of this evaluation.

Table 7. Manufacturing variety coefficient values

\begin{tabular}{|c|c|c|c|c|c|c|c|c|}
\hline \multirow{3}{*}{$\begin{array}{c}\text { Pressure } \\
(\mathbf{m})\end{array}$} & \multicolumn{8}{|c|}{$\mathrm{CV}_{\text {cal }}$ and Classification values } \\
\hline & \multicolumn{2}{|c|}{ A (local) } & \multicolumn{2}{|c|}{ B (local) } & \multicolumn{2}{|c|}{ C (foreign) } & \multicolumn{2}{|c|}{ D (foreign) } \\
\hline & 13.27 & $W$ & 5.68 & G & 3.74 & VG & 1.39 & VG \\
\hline 10 & 8.46 & $M$ & 3.33 & VG & 1.80 & VG & 1.57 & VG \\
\hline 15 & 5.60 & $G$ & 2.64 & VG & 2.50 & VG & 1.89 & VG \\
\hline 20 & 6.16 & $G$ & 1.62 & VG & 1.34 & VG & 2.25 & VG \\
\hline
\end{tabular}

While the A emitter with an operating pressure of $5 \mathrm{~m}$ yielded a high (13.27) CV value, it was classified as "weak". Similarly, while the same emitter took on the value of "moderate with a load of 8.46 at a pressure load of $10 \mathrm{~m}$, it was classified as "good" at pressure loads of $15 \mathrm{~m}$ and $20 \mathrm{~m}$. The classification change interval ranged between "good" and "very good" for the B emitter as well even though the changes were not as dramatic as those of the emitter A. The change interval for the manufacturing variety coefficients under different pressure loads for exported emitters $C$ and D was not very high with the lowest value of 1.34, highest value of 3.74 and a classification of "very good". Demir and Yürdem (2000) carried out a study in which a total of 32 emitters (22 without pressure regulator, 6 with pressure regulator and 4 with on-line emitters) were subject to tests under 5 different operating pressures and controlled laboratory conditions. It was observed as a result of the evaluation based on manufacturing variety coefficients that the emitters without pressure regulator were classified as "unacceptable" and "moderately perfect". The changes in CV values subject to pressure in the present study were in accordance with the findings of other researchers in literature. Even though the manufacturing variety coefficients of emitters vary between $2-15 \%$, it is possible to obtain higher values (Çiçek, 2015). The CV values acquired in this study remained in the limits indicated by the researchers.

\section{Emitter uniformity (EU)}

The emitter uniformity coefficients for the emitters subject to the tests in the study were calculated using Eq.3 and evaluated in accordance with ASAE (1994) and the acquired results together with the classification results are given in Table 8. As can be 
seen upon examining the table that the emitter uniformity coefficients displayed increasing or decreasing changes. Whereas an increase was observed in emitters A, B and $\mathrm{C}$ subject to an increase in pressure, the converse was true for the emitter D. Tekin et al. (2016) carried out a study in which the emitter uniformity coefficient decreased at all pressures applied, only the results for emitter D were in accordance while the contrary was observed for all other emitters and the acquired results were not in accordance with the findings of other researchers. This is due to the fact that different brand laterals and emitters have been used.

Table 8. Emitter Uniformity, EU

\begin{tabular}{c|cc|cc|cc|cc}
\hline \multirow{2}{*}{$\begin{array}{c}\text { Pressure } \\
(\mathbf{m})\end{array}$} & \multicolumn{7}{|c}{ EUcal and classification values } \\
\cline { 2 - 8 } & \multicolumn{2}{|c|}{ A (local) } & \multicolumn{2}{|c}{ B (local) } & \multicolumn{2}{c}{ C (foreign) } & \multicolumn{2}{c}{ D (foreign) } \\
\hline 5 & 85.49 & $G$ & 94.53 & $V G$ & 95.64 & $V G$ & 98.27 & $V G$ \\
10 & 91.86 & $G$ & 95.46 & $V G$ & 98.11 & $V G$ & 97.82 & $V G$ \\
15 & 92.69 & $G$ & 96.50 & $V G$ & 96.93 & $V G$ & 97.87 & $V G$ \\
20 & 93.23 & $G$ & 97.93 & $V G$ & 98.39 & $V G$ & 97.37 & $V G$ \\
\hline
\end{tabular}

While emitter A was below the value of $94 \%$ for all applied pressures and took on the classification of "good", the other emitters were classified as "very good". The lowest emitter uniformity coefficient was determined as 85.49 for emitter A under a pressure load of $5 \mathrm{~m}$, while the highest value was determined as 98.39 for emitter $\mathrm{C}$ under a pressure load of $20 \mathrm{~m}$. Emitter uniformity coefficients were classified as "good" and "very good" for emitter A as was the case according to the findings of Özekici and Bozkurt (1996), the other emitters remained above $94 \%$ and were classified as "very good" in accordance with the results of studies by Çamoğlu and Yavuz (2004), Tekin et al. (2016). Uygan and Çetin (2015) carried out a study in which the emitter uniformity coefficient varied between $80-99 \%$ in plants using the emitter system in the EskişehirSakarya region.

\section{Irrigation water uniform distribution coefficient $(C U)$}

The compliance of the irrigation water uniform distribution coefficients of emitters were calculated using Eq.4 and evaluated according to ASAE (1994) and given in Table 9. While all coefficients obtained in the study were classified as "very good", only emitter A took on the "good" classification under a pressure load of $5 \mathrm{~m}$. In general, $\mathrm{Cu}$ values increased with increasing pressure for emitters $\mathrm{A}, \mathrm{B}$ and $\mathrm{C}$, while all values were similar for emitter D under all pressure values. Çamoğlu and Yavuz (2004) determined the average CU value as 97.41, while Tekin et al. (2016) determined the average CU value as $97.20 \%$ and classified it as "very good". Based on these results, they concluded that the operating pressure value has an impact on the uniformity coefficient.

\section{Statistical uniformity (Us)}

The compliance of statistical uniformity coefficient values for the emitters was calculated using Eq.5 and evaluated subject to ASAE (1994) and the acquired Us coefficients are given in Table 10. As can be seen when the table is examined that the lowest statistical uniformity coefficient was obtained as $5 \mathrm{~m}$ for emitter A under a pressure load of as 86.73 , while the highest value was obtained as 98.66 for emitter C 
under a pressure load of $20 \mathrm{~m}$. In this case, the statistical uniformity classification values varied between "good" and "very good". In general, the Us values were determined to be under $94 \%$ only for emitter A under pressure loads of 5-10 and $20 \mathrm{~m}$, while the average Us value was determined as above $94 \%$ and was classified as "very good". Çamoğlu and Yavuz (2004) carried out a study in which this value was determined as $97.11 \%$, while Tekin et al. (2016) determined it as 96.49 .

Table 9. Irrigation Water Uniform Distribution Coefficients (CU)

\begin{tabular}{c|cc|cc|cc|cc}
\hline \multirow{2}{*}{ Pressure (m) } & \multicolumn{6}{|c}{ Coefficient of irrigation water distrubution uniformity (CU), \%, and classification values } \\
\cline { 2 - 8 } & \multicolumn{2}{|c|}{ A (local) } & \multicolumn{2}{c|}{ B (local) } & \multicolumn{2}{c}{ C (foreign) } & \multicolumn{2}{c}{ D (foreign) } \\
\hline 5 & 89.41 & $G$ & 95.47 & $V G$ & 97.02 & $V G$ & 98.89 & $V G$ \\
10 & 93.25 & $V G$ & 97.34 & $V G$ & 98.57 & $V G$ & 98.75 & $V G$ \\
15 & 95.53 & $V G$ & 97.90 & $V G$ & 98.00 & $V G$ & 98.49 & $V G$ \\
20 & 95.08 & $V G$ & 98.71 & $V G$ & 98.93 & $V G$ & 98.21 & $V G$ \\
\hline
\end{tabular}

Table 10. Coefficients of Statistical Uniformity (Us)

\begin{tabular}{c|cc|cc|cc|cc}
\hline \multirow{2}{*}{ Pressure (m) } & \multicolumn{7}{|c}{ Us (\%) classification values } \\
\cline { 2 - 8 } & \multicolumn{2}{|c|}{ A (local) } & \multicolumn{2}{c}{ B (local) } & \multicolumn{2}{c}{ C (foreign) } & \multicolumn{2}{c}{ D (foreign) } \\
\hline 5 & 86.73 & $G$ & 94.32 & $G$ & 96.26 & $V G$ & 98.61 & $V G$ \\
10 & 91.54 & $G$ & 96.67 & $V G$ & 98.20 & $V G$ & 98.43 & $V G$ \\
15 & 94.40 & $G$ & 97.36 & $V G$ & 97.50 & $V G$ & 98.11 & $V G$ \\
20 & 93.84 & $G$ & 98.38 & $V G$ & 98.66 & $V G$ & 97.75 & $V G$ \\
\hline
\end{tabular}

Selvaperumal et al. (2019) conducted a study in India on drip irrigation system in order to determine manufacturing variety coefficient (CV), uniformity coefficient (UC) and statistical uniformity (US) with the soil moisture distribution. Researchers declared that the coefficient of variation (CV) was obtained 0.0207 percent at a constant pressure of $50.66 \mathrm{kPa}$, statistical uniformity (US) as 97 percent and coefficient of uniformity (CU) as 0.9518 . While US and CU values were consistent with our findings, $\mathrm{CV}$ values were found to be very low.

\section{Conclusion}

The fact that this study is conducted for the first time in the region is important in terms of guiding the future studies on this subject. The fact that this study is conducted for the first time in the region is important in terms of guiding the future studies on this subject. Beneficiaries who will benefit from the study outputs will be able to make more conscious choice in system planning, installation and dripper selection and thus contribute to the protection of water resources. It is expected from the drip irrigation system to provide the required performance, to be operated profitably and to provide the sufficient amount of water to the plant under optimum conditions with the best system hydraulic and flow parameters. Lowest values of the manufacturing variety coefficients which are among the most important factors that make up the system parameters lead to low flow rate variations between emitters and the ability to provide sufficient water to the plant root region. High values of Emitter Uniformity (EU), Cristiansen Uniformity Coefficient (CU) and statistical uniformity coefficients (Us) for all emitters increases the success of irrigation while also resulting in a uniform plant development and 
optimum increase in yield. Due to the aforementioned reasons, all factors with adverse impacts on hydraulic performance should be eliminated when setting up the drip irrigation system and the system should be operated efficiently based on the principle of efficacy.

Acknowledgements. This study was carried out at the Siirt University, Biosystems Engineering Department Irrigation Laboratory in Siirt/TURKEY, using a test table manufactured under the scope of the 2017-SIUZIR-53 Research Project supported by Siirt University Scientific Research Project Office.

\section{REFERENCES}

[1] Altın, F. (2009): The Effect of Dripper Manufacturing Differences on System Design. Ege Uni. Graduate School of Natural and Applied Science. Department of Agriculture Structure and Irrigation. M.Sc Thesis. p:84. (in Turkish).

[2] Anonymous (2004): Agricultural Irrigation Methods. - Ministry of Agriculture and Rural Affairs, Publication Department, Farmer Training Series 7. (in Turkish).

[3] ASAE (1994): Design and Installation of Microirrigation Systems. - ASAE EP405.1 Dec.93: 724-727.

[4] ASAE (2002): Design and Installation of Microirrigation Systems. - ASAE EP405.1 Dec.01: 903-907.

[5] Baştuğ, R., Uzun, İ., Hakgören, F. (1998): Effects of different irrigation methods on yield, quality and water usage in vines in Antalya conditions. - Akdeniz University, Journal of Agriculture Faculty 11(1): 81-89. (in Turkish).

[6] Bozkurt, S. (1996): The Effects of Manufacturing Differences on the Equal Distribution of in-line Drippers. - Çukurova Uni. Institute of Natural and Applied Science. Department of Agriculture Structure and Irrigation. M.Sc Thesis. p:116. (in Turkish).

[7] Bralts, V. F., Kesner, C. D. (1983): Drip Irrigation Field Uniformity Estimation. Transactions of the ASAE.26(5): 1369-1374.

[8] Bralts, V. F. (1986): Operational Principles-Field Performance and Evaluation. - In: Nakayama, F. S., Bucks, D. A. (eds.) Trickle Irrigation for Crop Production. Elsevier Science Publisher, B. V. The Netherlands: 216-223.

[9] Bralts, V., Edwards, D. M., Wu, I. P. (1987): Drip Irrigation Design and Evaluation Based on the Statistical Uniformity Concept. - Advances in Irrigation 4: 72.

[10] Christiansen, J. E. (1942): Hydraulic of Springling Systems for Irrigation. - Trans. ASCE 107: 221-239.

[11] Çamoğlu, G., Yavuz, M. Y. (2004): Comparison of domestic and foreign production drippers in terms of irrigation performance. - Uludağ Uni. Journal of Agricultural Faculty 18(1):181-191. (in Turkish).

[12] Çiçek, Y. (2015): Investigation of Water Dispersion Smoothness in Drip Irrigation Systems Used in Olive Trees around İzmir. - Selçuk Uni. Graduate School of Natural Sciences, Department of Agriculture Structure and Irrigation. M.Sc Thesis. p:54. (in Turkish).

[13] Demir, V., Yürdem, H. (2000): Technical Characteristics and Manufacturing Differences of drippers with different production features produced and widely used in Turkey. - Ege Uni. Journal of Agriculture Faculty 37(2): 85-92. (in Turkish).

[14] Elamin, A. W. M., Abd Eldaiam, A. M., Abdalla, N. A., Hussain, M. E. (2017): Hydraulic performance of drip irrigation system under different emitter types, and operating pressures using treated wastewater at Khartoum state. - International Journal of Development and Sustainability 6(9): 1086-1095.

[15] Karaca, Y. (2008): Determination of Extension Distance of Circular Section Tubes of Drip Irrigation according to Different Dripper Range. - Namık Kemal Uni. Institute of 
Natural and Applied Science. Department of Agricultural Structure and Irrigation. M.Sc Thesis, p: 64, Tekirdağ.

[16] Keller, J., Karmeli, D. (1974): Trickle Irrigation Design Parameters. - Trans of the ASAE 17(4): 678-684.

[17] Kırnak, H., Doğan, E., Demir, S., Yalçın, S. (2004): Determination of Hyraulic Performance of Trickle Irrigation Emitters Used in Irrigation Systems in the Harran Plain. - Tr. J. of Agr. and For. 28: 223-230.

[18] Korukçu, A. (1980): A Research on Determination of Side Pipe Lengths in Drip Irrigation. - Ankara Uni. Ankara Uni. Publications 742, p:75 Ankara. (in Turkish).

[19] Mohammed, M. M. Z. (2018): Evaluation of Drip Irrigation Method Used for Irrigation of Cherry Gardens in Konya-Akşehir District. - Selçuk Uni. Graduate School of Natural Sciences, Department of Agriculture Structure and Irrigation. M.Sc Thesis. p: 44. (in Turkish).

[20] Özekici, B., Sneed, R. E. (1995): Manufacturing Various Trickle Irrigation On-Line Emitters. - ASAE 0883-8542: 1102-0235.

[21] Özekici, B., Bozkurt, S. (1996): Determination of Hydraulic Performance of in-line Drippers. - Tr. J. of Agriculture and Forestry 23(1): 19-24.

[22] Selvaperumal, A., Sujitha, E., Muthuchami, I. (2019): Evaluation of uniformity Coefficient and Soil Moisture Distrubution under Drip Irrigation System. - Current Journal of Applied Science and Technology 34(5): 1-9. Article no.CJAST.48187, ISSN:2457-1024 (Past name: British Journal of Applied Science\&Technology, Past ISSN:2231-0843, NLM ID:10166454).

[23] Solomon, K. (1979): Variability of Sprinkler Coefficient of Uniformity Test Results. Transactions of the ASAE 22: 1078-1086.

[24] Tekin, S., Boyacı, S., Sezen, S. M., Gönen, E., Soylu, E., Soyugüzel, E., Özge, Z., Ketenci, A. M., Üstün, Y. (2016): Evaluation of Hydraulic Properties of Drip Irrigation Drippers which are Commonly Used in Kahramanmaraş Region. - KSU J. Nat. Sci. 19(4): 445-453. 2016, Research article. (in Turkish).

[25] Tüzel, H. (1990): A Study on Some Technical Properties and Project Criteria of Domestic Drip and Low Pressure Sprinkler Systems. - Ege Uni. Graduate School of Natural and Applied Science. Department of Agriculture Structure and Irrigation. Ph.D Thesis. p: 95. (in Turkish).

[26] Tüzel, H. (1993): Evaluation of Irrigation Uniformity in Drip Irrigation Systems. - Ege Univ. Journal of Agriculture Faculty 30: 119-126. (in Turkish).

[27] Uygan, D., Çetin, Ö. (2015): Evaluation of performance indicators in some drip irrigation systems installed in Eskişehir and Sakarya Provinces-Drip irrigation performance indicators. - Journal of Soil \& Water 4(1): 27-35. (in Turkish).

[28] Üğlü, G., Tanrıverdi, Ç. (2013): Hydrolic Performance Analysis of in-line Drippers. Agriculture for Life, Life for Agriculture, 5-8 June, 2013, Bucharest.

[29] Ünal, Y. (2011): Determination of Optimum Lateral Lengths of Some Drip Irrigation Pipes in Domestic Production. - Selçuk Uni. Graduate School of Natural Sciences, Department of Agriculture Structure and Irrigation. M.Sc Thesis. p: 55. (in Turkish).

[30] Wu, I. P., Gittlin, H. M. (1974): Drip Irrigation Design Based on Uniformity. Transactions of the ASAE 17(3): 157-168.

[31] Wu, I. P., Howell, T. A., Hiler, E. A. (1979): Hydraulic Design of Drip Irrigation Systems. - Hawai Agricultural Experiment Station, University of Hawaii, Technical Bulletin No.105.

[32] Yeeshu, K. D., Verma, V. P., Sinha, J. (LM-10161), Verma, P. D. (2014): Hydraulic Performance of Drip Irrigation System under Different Operating Pressures. Agricultural Engineering Today 38(3): 20-23. Print ISSN: 0970-2962. Online ISSN: 2230-7265. 